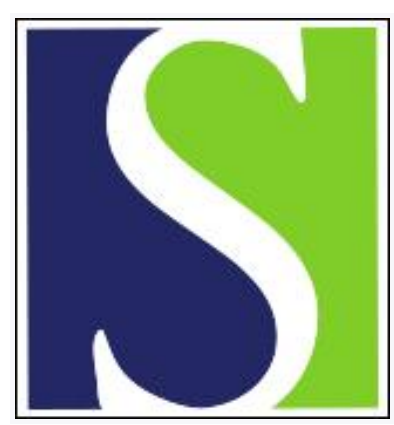

Scand J Work Environ Health 1984;10(6):487-493

https://doi.org/10.5271/sjweh.2311

Issue date: Dec 1984

\title{
Aggravation of lung disease.
}

by Abrams HK

This article in PubMed: www.ncbi.nlm.nih.gov/pubmed/6398915

\section{(c) (1)}




\title{
Aggravation of lung disease
}

\author{
by Herbert $\mathrm{K}$ Abrams, MD, $\mathrm{MPH}^{1}$
}

\begin{abstract}
ABRAMS HK. Aggravation of lung disease. Scand $J$ Work Environ Health 10 (1984) 487-493. The chronic respiratory diseases are a pervasive cause of morbidity and mortality. In the developed countries the chronic nonspecific respiratory diseases (CNRD), eg, chronic bronchitis, emphysema, bronchial asthma, are a major cause of morbidity and mortality. They have been increasing during a period when, in many countries, there has been a decline in total mortality rates and in certain major chronic illnesses such as coronary heart disease. In many developing countries, acute and chronic respiratory diseases are leading causes of death with chronic bronchitis as a major cause of disability. The boundary between occupationally caused and "work-related" chronic lung diseases is indistinct, reflecting the multifactorial nature of the diseases. This report focuses primarily on the CNRD, and the work-related risk factors which play a role in their etiology and/or aggravation. These factors include specific work exposures such as inhaled noxious materials and other work conditions, immunologic considerations, combined exposures in the work and community environment, societal trends such as industrialization and urbanization, behavioral patterns, stress, social support, and other socioeconomic elements. The available evidence is examined, and directions are indicated for further research for the identification of those factors in the environment which initiate, potentiate, or aggravate CNRD and for the development of measures for the prevention of disability and premature death.
\end{abstract}

Key terms:

\section{Only 26 years ago, Fletcher (15) wrote that}

In Great Britain we believe that chronic bronchitis is a disease that frequently leads to progressive obstructive pulmonary emphysema, which may prove fatal; and we regard the syndrome of chronic bronchitis and emphysema as the commonest cause of respiratory disability in our working population [p 368].

Mortality in the cities was twice that in the countryside. Mortality in social class $\mathrm{V}$ was more than five times that in social class 1 . Since the social gradient was the same for both sexes,

... it must therefore be due to some general environmental rather than occupational influence, and since the unskilled laborers tend to live in the more crowded and smokey parts of our cities, it is quite probable that this is again an effect of atmospheric pollution. Overcrowding with inadequate medical care and easy transmission of infections may also be playing a part [p 369].

Thus Fletcher identified some of the factors involved in chronic nonspecific respiratory diseases.

The problem of aggravation takes one into multifarious realms of theory and fact, ranging from physical and chemical exposures to social and emotional factors, with detours into immunology, heredity, be-

\footnotetext{
1 Department of Family and Community Medicine, College of Medicine, University of Arizona, Tucson, Arizona 85724, United States.
}

Reprint requests to: Prof HK Abrams, Department of Family and Community Medicine, College of Medicine, University of Arizona, Tucson, AZ 85724, USA. havior, and medical care. The problem is not as simple as the aggravation of silicosis by the tubercle bacillus.

In identifying factors that may aggravate chronic work-related lung disease, one must approach the subject comprehensively. The factors may be listed as follows:

Work conditions: noxious dusts, gases, vapors, hard labor

Host susceptibility: immunologic/atopic (immunoglobulin $\mathrm{E}$ tendency), protease inhibiting phenotype $\mathbf{Z}$ (alpha antitrypsin deficiency), increased bronchial reactivity

Community conditions: industrialization/urbanization, air pollution

\section{Childhood respiratory disorders}

Socioeconomic factors: education, environment, medical care, nutrition, housing, psychosocial stress

Behavioral factors: cigarette smoking, alcoholism.

Schilling (39) puts the issue simply:

There is an increased morbidity and mortality from chronic bronchitis in certain groups which have in common hard physical work and air pollution, both at work and in the general environment, as well as adverse socioeconomic factors. The available evidence suggests that occupational factors exacerbate rather than cause this disease. Nevertheless, there can be little doubt that a chronic bronchitic should 
not be exposed to airborne dusts or irritant gases and fumes, nor be employed on heavy work if respiratory symptoms are not to be worsened [p 59].

Harriet Hardy, in her recently published memoirs (18), describes how she was "... struck by the frequent occurrence of bronchitis. This disease is closely associated with industrialization and crowding in cities, with poverty and poor nutrition, and also with smoking habits [p 104]."

It is not possible to classify occupational exposures precisely as "causative" or "aggravating." The evidence is sufficient that industry offers both, and the same agent which initiates disease also aggravates it upon continuing exposure.

\section{Occupational factors}

One conclusion of the International Symposium on Ecology of CNRD [chronic nonspecific respiratory diseases] (58) in 1971, was that “. . . contrary to expectation, among the factors influencing CNRD, working environment is not decisive [p 69]." The criterion of "decisiveness" poses a formidable barrier to proving work-relatedness. Nevertheless, even in the same volume, are many reports such as "... agents in cotton dust and in cigarette smoke are additive or even synergistic in producing $C B$ [chronic bronchitis] in men and women employed in the textile industry of North Carolina, USA [p 81]" or, from Poland's textile industry, “. . . high concentrations of dust and air microflora are the main cause of CNRD ... [p 75]" or, from Belgium, "symptoms of $\mathrm{CB}$ appeared to be more frequent in coal miners than in two other occupational groups [p 95]." Chronic nonspecific respiratory diseases also correlate positively with age, smoking, and various chemical and dust exposures (58).

The very high incidence of chronic bronchitis and emphysema caused by dusts in steel workers and coal miners independent of smoking has been confirmed in many studies (11).

An illustration of the complexity of the problems can be found in the experiences of farm workers. Farmers in England, for example, have less respiratory diseases than do urban dwellers. However, "farm workers" in the United States usually mean migrant farm workers, a population made up primarily of minority ethnic groups and poor whites. They have a death rate from respiratory disease, usually pneumonia, that is much higher than that of "farmers" (farm owners or managers) (7).

In Papua, New Guinea, there are three million people moving rapidly from rural tribal life into modern industry. It is a nation of migrant workers. Here also the chronic bronchitis rate is high, and pneumonia is the first cause of death. Cor pulmonale is not uncommon $(1,42,54)$.

The prevalence of indicators of chronic nonspecific respiratory diseases among grain handlers is also a large area of concern (12).
In contrast to Schilling and numerous other investigators, Parkes (34) discounts the role of occupational exposures in either the causation or aggravation of chronic bronchitis. He decries the use of the term "industrial bronchitis." He cites references to support his contention that "there is ... no convincing evidence to show that chronic obstructive bronchitis... nor associated respiratory disability are directly and consistently attributable to such [occupational] exposure [p 21]." He places emphasis on smoking and social factors as the "principal causes" and adds that: "Although general environmental pollution may provoke exacerbation of existing bronchitis it has not been clearly shown to be an initiating cause [p 21]."

Cigarette smoking is universally agreed on as both an initiator and aggravator of chronic bronchitis. It is a frequent confounder in studies of chronic nonspecific respiratory diseases because of the high prevalence of smoking generally and the especially high prevalence among blue-collar workers, who are the most at risk from occupational and community exposures.

An example of how this confusion affects real life situations is the following decision of a compensation board (44). Their established rule is that: "Where a person claims compensation in respect of bronchitis and emphysema the Board considers that the history of ... significant cigarette smoking raises a strong inference that this condition is due to the smoking and not to the nature of his employment [p 438]."

However, in the case of a miner, the Medical Review Panel found that the claimant was a "very light smoker" and stated that "... the long period of underground mining must have at least aggravated the condition and could have caused it... the Panel feels his disease was caused by his employment [pp 438-439]."

In the end the claimant was denied compensation by the Vancouver Compensation Board which felt that the Medical Panel's concern that years of mining may have "aggravated" a disease caused by "light" smoking was "speculative" (44).

Despite the polemics, the clinical recognition of occupational bronchitis is well founded. Numerous reports associate bronchitis and excess mortality from emphysema with diverse occupations $(11,24,31,58)$.

One need not permit the cloud of smoking or seductive social factors to obscure the fact that noxious dusts and chemicals may also cause and exacerbate chronic bronchitis and other pulmonary disorders.

\section{Combined exposures}

Combined exposure in the workplace is probably the norm. Most workers are exposed to combinations of chemicals or chemicals with physical exposures or chemical or physical exposures with physical exertion and fatigue. When these are also combined with 
socioeconomic factors such as malnutrition or poor community environment, a hazardous mixture results.

Foundry workers, steel workers, smelter workers, miners, coke oven workers, welders, farm workers, firefighters, and many others are exposed to multiple chemicals plus extremes of heat and cold. The biologic effects of combined exposures are extremely complex. In relation to chronic nonspecific respiratory diseases the combined effect of smoking with dusts and irritants is best known. But there is increasing evidence of combined additive and synergistic effects of many combinations of chemicals and work conditions - in animal research, in in vitro experiments, and, to a small extent, in epidemiologic studies (56).

\section{Air pollution}

The most dramatic examples of "aggravation" have been the community pollution episodes such as in the Meuse Valley in Belgium in 1931; in Donora, Pennsylvania in the United States, in 1948; and in London, England, in 1952. During these events, chronically ill (mostly elderly) people with chronic cardiovascular and/or respiratory diseases were affected severely. However, many others also suffered $(2,5,29)$.

Acute episodes often leave a residuum of longterm effects with survivors. For example, nine years after the Donora episode, it was found that persons reporting illness during the episode had higher subsequent mortality rates and a greater prevalence of disease than did those who were not ill (9).

Bronchial asthma has been called the "litmus" of bronchial reactivity in response to air pollution. There may be a tenfold greater occurrence of bronchial asthma attacks in cities during days of high pollution. Air pollution may also enhance the asthmatic patient's reactivity to other stimuli. The bronchitis rate in Denmark, an agrarian country, is one-sixth that of Great Britain. Wyatt (57) cites Lave \& Seskin, who concluded that the significant variable for fatal cases of bronchitis was air pollution [p 27], and Kasper, who utilized pulmonary heart disease as a parameter and reported a twofold higher frequency in heavily polluted areas of Czechoslovakia [p 127].

An autopsy study of 300 lungs from the polluted city of St Louis, Missouri, in the United States, as contrasted with clean-air Winnipeg, Canada, found a considerably greater prevalence of emphysema in St Louis. The investigators concluded that "... emphysema may be related to a synergistic effect of smoking and environmental pollution [p 666]" (22).

Winkelstein et al (53) attempted to separate the variables of air pollution and socioeconomic status. Their conclusion was that the effects of air pollution were at least partially independent of economic factors.
Increased concentrations of the sulfur oxide-particulate complex have been consistently associated with greater mortality during episodes of pollution and with the aggravation of symptoms in those with heart and lung disease. In polluted cities there is a greater prevalence of chronic respiratory disease among adults and an increased incidence of acute respiratory disease and depressed lung function among children.

The health effects of photochemical oxidants have not been as well documented for human subjects. Studies in the United States (Los Angeles) and Japan associate high concentrations with eye irritation, cough, and chest discomfort, especially in exercising groups. In experimental animals photochemical oxidants cause structural changes in lung tissue and increased susceptibility to respiratory infection (2).

Air quality standards have emerged from the numerous studies of air pollution effects, and, since the application of these standards in Britain, the United States, and other countries, it is unlikely that acute disasters such as Donora will recur $(2,20,27)$. However the long-term effects of lower-level exposures, the possibility of high exposures from point sources, and the poorly controlled high levels of pollution being reported from some of the developing countries pose many of today's problems.

\section{Individual susceptibility}

Except for very large exposures "aggravation" involves individual susceptibility. As controls of exposure improve, individual susceptibility becomes more important. Why do some workers escape disease despite high exposures to inhaled particles? Why do others succumb to relatively low exposures? Why do some individuals with acute symptoms proceed to chronic disease? What protective factors are operative?

The evaluation of susceptibility involves a consideration of (i) the exposure levels in the workplace, (ii) the relative degree of retention and toxicity of the dust particles or the toxicity of the chemicals, (iii) the physical effort involved in the job, (iv) immunologic or atopic factors, (v) genetic factors, (vi) behavioral problems, ie, smoking, alcohol, etc, and (vii) social and environmental correlations. Liddell \& Miller (28) have summarized the issue well. There are no good answers to these questions as yet. ${ }^{2}$

\footnotetext{
2 Bronchial reactivity deserves special mention as a risk factor. While there may be genetic and immunologic components, Dr Ben Burrows, in a private communication, has reminded that ozone, and perhaps other agents, can lead to a state of nonspecific bronchial reactivity which would then predispose the lung to adverse reactions to other exposures.
} 


\section{The acute/chronic relationship}

The relationship of acute to chronic lung disease is at the heart of the subject of aggravation. Acute chemical exposures may lead to long-lasting effects. But the more subtle low-level exposures are the basis of controversy.

What are the sequelae in workers who are exposed to large but not fatal doses of some of the powerful industrial poisons, for example, phosgene, chlorine, nitrogen oxides? Latge doses of certain pulmonary irritants or repeated low doses may lead to chronic pathology and symptoms (17).

The byssinosis story provides an interesting example of the controversy around acute and chronic relationships. Schilling (39) said byssinosis can progress to irreversible impairment of pulmonary function. Similarly the Shirley Institute (British) review (41) observes:

\begin{abstract}
A proportion of these subjects may then progress... (and) ... in the final stages ... the disability persists even when away from the mill and becomes permanent ... the definition ... in most of the literature ... stresses the progressive nature of the disease. This presupposes that the acute and chronic effects of textile dusts on human lungs are linked, but ... this has not been shown beyond doubt ... to do so would need a long-term prospective study... however, in favor of ... progression from the acute to the chronic type of byssinosis is the realization that acute airway responses to occupational asthma may ... lead to long-term ... airway obstruction, even after exposure ... has ceased [p 13].
\end{abstract}

The report (32) of the National Research Council in the United States in 1982 presents a different view. Byssinosis is defined only as an acute disease: "...one or more acute respiratory symptoms associated with exposure to cotton, flax, and hemp dust in the workplace [p 9]." The report contends that the connection between the acute symptoms of byssinosis and chronic bronchitis or emphysema has not been demonstrated.

Kilburn, however, wrote a "Minority Report" (32). He cited the recognition of cotton dust disorder 300 years ago:

Long before the advent of cigarette smoking as a 'confounding factor' ... the linkage of acute response to a chronic disease was established. In fact, the linkage goes back to Ramazini and was amplified by Thackrah and by Kay in the 19th century and by A. B. Hill in the 1930s [p 136] ... the lessons of history must be heeded and ... we must assume the data is real which pictures byssinosis as a chronic impairment of respiratory function related by symptoms and pathology to chronic bronchitis with a pattern of airway obstruction related to employment in the cotton textile industry [p 141].

\section{Childhood experience}

"Conditioning" or "imprintment" factors during early life play a role in subsequent adult respiratory illness. Environment, infection, and perhaps nutritional experiences in the formative years are important.

Surveys of children show the influence of factors other than smoking and occupation (36). "A survey of respiratory disease in over 10000 children ages 6-10 years living in contrasting urban and rural areas of England and Wales showed pronounced social gradient in the frequency of chronic cough, history of bronchitis, and in disease of ears and nose. A consistent rise in the frequency of chest conditions with increasing local levels of air pollution was most clearly seen only among the children of skilled and unskilled workers... [p 213]" (10).

Though smoking and dusty work may be dominant factors in adult bronchitis, "air pollution may determine the onset or evolution of the disease in both young and old [p 217]' (10).

Studies in Papua, New Guinea, where people are exposed to smoke in their unventilated thatched huts from birth, show a high rate of respiratory infections and chronic bronchitis (54).

Burrows et al (4), in a study of 2600 individuals in Arizona, came to the conclusion that: "... pediatric respiratory disorders may be an important risk factor for the subsequent development of chronic airways disease in adult life [p 220]."

\section{Socioeconomic factors}

Social class and its myriad of inferences are important considerations in the aggravation of disease. Observations in all parts of the world have demonstrated a social gradient in the burden of disease.

Fox \& Adelstein (16) attempted to dissect the British Registrar General's data to sort out the relative impact of occupation as compared with that of other environmental elements. They reexamined the figures that showed similar standardized mortality ratios for chronic bronchitis in men and their wives and that implied the importance of factors other than occupation. They showed, for example, the great increase in the proportion of women who are working in industry. Furthermore, they found that a surprising proportion of women participated in the same occupation as their husbands or in occupations with similar exposures. They called attention to the large sex differences in the consumption of cigarettes and alcohol. Bronchitis death rates for men are more than four times those for married women of the same age. By the process of social class standardization, ie, by comparing mortality rates for men in an occupational order with men in the same social class rather than with all men, they were able to tease out the relative effect of occupation versus other factors. For example, stevedores had a standardized mortality ratio that was $40 \%$ higher than the national rates, but their ratio was only $6 \%$ higher than that for men in social class V. At the other end of the scale doctors' 
rates were $19 \%$ lower than that for all men but $5 \%$ higher than that for men in class I.

For each group of diseases they calculated that percentage of mortality that was occupationally related versus the proportion due to other factors. Overall, $18 \%$ appeared to be related to occupation and $82 \%$ to "way of life," the proportion for respiratory disease being $28 \%$ occupational and $72 \%$ other.

Many studies associate low social status or low occupational status with respiratory disease, as well as with other conditions $(6,25,30,52)$.

\section{Psychosocial factors}

Cassell (8), influenced by Dubos (13), attempted to analyze the effect of psychosocial factors on health in terms of host resistance, or individual susceptibility to disease. His main thesis was that stress is a bodily state, not a component of the environment. It results from the interaction of the organism with noxious stimuli or circumstances. These (neuroendocrine) changes enhance the susceptibility to disease. Psychosocial factors act as conditioning or predisposing factors rather than as direct pathogenic agents.

Social disorganization is a large factor in this picture. Social support is a source of protection. Cassell (8) called for a change in preventive strategy, aiming at "further identification... and ... modification of these categories of psychosocial factors rather than on screening and early detection [p 121]." It is more feasible to improve and strengthen social supports than to reduce the exposure to stressors.

Cassell emphasized the importance of epidemiology focusing on the environment, rather than on the individual. One of his students (SL Syme, in an unpublished report called "The Social Environment and Disease: Towards a Proper Epidemiology') pointed out that epidemiologists have tended to focus

\begin{abstract}
... on the individual's risk status, we have urged that individuals change their behavior and we have adopted a disease classification scheme that has been developed primarily for the diagnosis and treatment of individual diseases... this focus prevents us from observing that different-appearing diseases have characteristics in common... as Cassell put it, when investigators are concerned with only one clinical entity, the features common to multiple disease manifestations tend to be overlooked [pp 24-25].
\end{abstract}

Although mortality rates overall have decreased in the developed countries, the social gap persists. That so many different kinds of diseases are more frequent in the lower classes indicates a relationship to generalized susceptibility and to compromises of the defense systems against disease (45).

Rather than attempting to identify specific risk factors for specific diseases, it may be more meaningful to identify those factors that affect general susceptibility to disease. To accomplish this goal one needs to identify variables that have a wide range of disease outcomes. Among these may be "life changes" associated with social and cultural mobility, social isolation, personal failure. These have been found to be associated with higher rates of respiratory illness and other conditions $(23,45,50)$.

\section{Occupational stress}

In a study of workers in a rubber tire and chemical plant in Michigan in the United States, House (21) concluded that occupational stress, especially "perceived stress," was significantly associated with selfreported symptoms of several physical disorders, including respiratory symptoms of cough and phlegm. He found "adverse additive effects" of self-reported exposure to hazardous agents (ie, dusts, fumes, chemicals) were evident for almost all health out-. comes. Exposure to these agents was negatively related to job satisfaction and self-esteem and positively related to smoking, neurotic symptoms, angina, ulcers, cough and phlegm, itch, and rash. He concluded that: "Psychosocial job stress may be especially hazardous to workers who are also exposed to physical-chemical or biological hazards in their work-environment [p 279]."”

\section{Nutrition}

Malnutrition is one of the components of low socioeconomic status that plays a role in reducing immunity to infection and possibly contributing to the burden of disease, including respiratory disorders. Numerous reports link malnutrition and increased susceptibility to infection. Malnutrition, particularly protein deficiency, affects the humoral (antibodymediated) and cell-mediated immune systems $(33,35$, $37,40)$.

\section{Alcohol}

Alcoholics are prone to respiratory infection and chronic lung disease. They also tend to smoke more and run the risk of repeated aspirations. There is evidence that alcohol abuse impairs the protective mechanisms of the airways and the ventilatory functions of the lung $(19,26)$.

\section{Prevention}

Despite differences in clinical manifestations and etiology, chronic nonspecific respiratory diseases have several common preventive considerations. They can be prevented, or arrested, by means of classic industrial hygiene procedures, early detection [Respirators have limited value and probably cannot be used by most people with lung disease (51), screening for sensitivity has limited value, and genetic screening is rarely justifiable.], worker and employer education, and optimum living conditions (55). 
An interesting idea that should be useful in prevention is the Sentinel Health Event concept, A Sentinel Health Event (Occupational) is a disease, disability, or untimely death which is occupationally related and the occurrence of which may (i) provide the impetus for epidemiologic or industrial hygiene studies or (ii) serve as a warning signal that industrial hygiene measures, personal protection, and/or medical attention is required. The proposal lists some 50 conditions, including occupational asthma (38). Chronic bronchitis is not listed, but it might be considered where appropriate.

In the case of newly introduced substances, Bouhuys states that the demonstration of acute effects on lung function "offers the only available basis for prevention and control [p 34]" (3).

\section{Research issues}

Many conferences on the subject of lung diseases have called for further research in all methodologies: epidemiologic, clinical, and animal studies $(11,14$, $47,48,49,59)$. The following list contains some of the problems and types of studies that have been suggested: (i) identification of host risk factors as a part of studies of workers exposed to hazardous inhalants, (ii) additional long-term longitudinal studies in industry to detect and quantify impaired respiratory health resulting from low level exposure to airborne chemical irritants, (iii) longitudinal studies to determine the relationship between childhood experiences and the development of chronic nonspecific respiratory diseases, (iv) development of registers of acute population exposures to encourage follow-up for long-range disease consequences, (v) studies of the natural history of occupational asthma in terms of the rate at which disease remits following the discontinuation of exposure and recurrence upon reexposure, (vi) studies to identify markers of transition from acute to chronic disease, (vii) surveillance systems to identify new workplace hazards, (viii) mechanisms by which environmental pollutants interact with infectious agents, (ix) community-based studies in which an industrial workforce forms a significant proportion of the population, and both active and retired workers would be reached (3), and (x) studies of the immunologic and pharmacological mechanisms in occupational asthma and related diseases. One of the most noteworthy of the recommendations is to "develop mechanisms" to facilitate interactions between scientists of diverse talents (48).

The psychosocial evidence points to a need for a consideration of how medical care systems and other social programs can counteract the destructive influences of adverse environments.

Turner-Warwick (46) summarizes some of the problems involved in dealing with work-related lung disease. These are problems inherent in occupational medicine. She calls for an "attitude of partnership" in the development of advanced technology in a civilized world which, " . . should never result in polarization of antagonism and mistrust where investigations are conducted in secret and results withheld through fear of misunderstanding or, worse, disguised by professional jargon... [p 9].",

The adoption of rational public policy is probably the most difficult of all problems, and one worthy of scientific research.

\section{Conclusion}

It is apparent that the aggravation of chronic nonspecific respiratory diseases is a multifactorial phenomenon, imbedded in a complex of living and work conditions. The problem calls for comprehensive social improvement, including workplace hygiene. Smith eloquently states, "The recognition that certain forms of ill health are socially produced and therefore possibly preventable is one of the most important sources of progressive political vitality ... today [p 343]" (43).

\section{References}

1. Abrams HK. Occupational health in Papua New Guinea. World Health Organization, Manila 1983.

2. American Thoracic Society, American Lung Association. Health effects of air pollution. New York, NY 1978.

3. Bouhuys A. Lung function measurements in occupational lung diseases. In: Dosman JA, Cotton DJ, ed. Occupational pulmonary disease. Academic Press, New York, NY 1980, pp $26 \& 34$.

4. Burrows B, Lebowitz MD, Knudson RF. Epidemiologic evidence that childhood problems predispose to airways disease in the adult. Pediatr Res 11 (1977) 218-220.

5. Calabrese EJ. Pollutants and high risk groups. Wiley, New York, NY 1978, pp 115-119.

6. Caplan RD, Cobb S, French JRP, Van Harrison R, Pinneau SR. Job demands and worker health. US Department of Health, Education and Welfare, Washington, DC 1975, pp 200-202.

7. Carlson ML, Petersen GR. Mortality of California agricultural workers. J Occup Med 20 (1978) 30-32.

8. Cassel $J$. The contribution of the social environment to host resistance. Am J Epidemiol 104 (1976) 107-123.

9. Ciocco A, Thompson DJ. A follow-up at Donora ten years after. Am J Publ Health 51 (1961) 155.

10. Colley JRT, Reid DD. Urban and social origins of childhood bronchitis in England and Wales. Br Med J 2 (1970) 213-217.

11. Commission of the European Communities. Researches on chronic respiratory disease. Luxembourg 1975, pp 168-177. (Medical symposium series no 18).

12. Dosman JA, Cotton DJ. Occupational pulmonary disease. Academic Press, New York, NY 1980, pp 26, 34, \& 194-196.

13. Dubos R. Man adapting. Yale University Press, New Haven, CT 1965, pp 164-165.

14. Environmental Protection Administration. Environmental Protection Administration workshop on environmentally related non-oncogenic lung diseases. Airlie, VA 1983. 
15. Fletcher CM. Disability and mortality from chronic bronchitis in relation to dust exposure. Arch Ind Health 18 (1958) 368-373.

16. Fox AJ, Adlestein AM. Occupational mortality: Work or way of life? J Epidemiol Community Health 32 (1978) $73-78$.

17. Gross $\mathbf{P}$, Rinehart WE, Hatch $\mathrm{T}$. Chronic pneumonitis caused by phosgene. Arch Environ Health 10 (1965) $768-775$.

18. Hardy HL. Challenging man-made disease. Praeger, New York, NY 1983.

19. Heinemann HO. Alcohol and the lung. Am J Med 63 (1977) $81-85$.

20. Holland WW, ed. Air pollution and respiratory disease. Technomonic, Westport, CT 1972, pp 30-31 \& 34-36.

21. House JS. Occupational stress and the mental and physical health of factory workers. Survey Research Center, University of Michigan, Ann Arbor, MI 1980. pp 231-286.

22. Ishikawa S, Bowden DH, Fisher V, Wyatt JP. The "emphysema profile" in two midwestern cities in North America. Arch Environ Health 18 (1969) 660666.

23. Jacobs MA, Spilken AZ, Norman MM, Anderson LS Life stress and respiratory illness. Psychosom Med 32 (1970) 233-242.

24. Lebowitz M. Epidemiologic recognition of occupational pulmonary diseases. Clin Chest Med 2 (1981): 3, $305-316$.

25. Lebowitz MD. The relationship of socio-environmental factors to the prevalence of obstructive lung diseases and other chronic conditions. $J$ Chronic Dis 30 (1977) 599-611.

26. Lebowitz MD. Respiratory symptoms and disease related to alcohol consumption. Am Rev Respir Dis 123 (1981) $16-19$

27. Lebowitz MD, Bendheim P, Cristea G, Markovitz D, Misiaszek J, Staniec M, Van Wyck D. The effect of air pollution and weather on lung function in exercising children and adolescents. Am Rev Respir Dis 109 (1974) 262-273.

28. Liddell D, Miller K. Individual susceptibility to inhaled particles. Scand J Work Environ Health 9 (1983) 1-8.

29. Mitchell RS, Judson FN, Moulding TS, Weiser P, Brock LL, Kelble DL, Pollard J. Health effects of urban air pollution J Am Med Assoc 242 (1979) 11631168.

30. Morgan WKC. Occupational bronchitis. Eur J Respir Dis 63 (1982): suppl 123, 117-127.

31. National Institute for Occupational Safety and Health. Occupational mortality in Washington state 19501979. Cincinnati, OH 1983.

32. National Research Council. Byssinosis, clinical and research issues. National Academy Press, Washington, DC 1982, pp 17-23.

33. Olson DP. Cold stress, malnutrition and disease resistance. In: Watson RR, ed. Nutrition, disease resistance and immune function. Marcel Dekker, New York, NY 1984, pp 385-393.

34. Parkes WR. Occupational lung disorders. Butterworths, London 1982, pp 18-22, 273, \& 415-453.

35. Petro TM, Watson RR, Bhattachargee JK. Immunity to bacterial pathogens in the protein-malnourished host. In: Watson RR, ed. Nutrition, disease resistance, and immune function. Marcel Dekker, New York, NY 1984, pp 35-52

36. Reid DD. Cited in the editorial "Beginnings of bronchitis." Br Med J 2 (1970) 190-191.

37. Reyes MA, Saravia NG, Watson RR, McMurray D. Effect of moderate malnutrition on immediate hypersensitivity of IgE levels in asthmatic children. J Allergy Clin Immunol 70 (1982) 94-100.
38. Rutstein DD, Mullan R, Frazier TM, Halperin WE, Melius JM, Sesito JP. Sentinel health events (occupational): A basis for physician recognition and public health surveillance. Am J Publ Health 73 (1983) 1054-1061.

39. Schilling RSF. Occupational health practice. Butterworths, London 1982, pp 29-60 \& 126.

40. Scrimshaw NS, Taylor CE, Gordon JE. Interactions of nutrition and infection. World Health Organization, Geneva 1968, p 3. (WHO monograph series 57).

41. Shirley Institute. Byssinosis, causative agent and clinical aspects. Manchester 1982, pp 8-13. (Publication no 543).

42. Sinnett PF, Whyte HM. Epidemiologic studies in a highland population of New Guinea: Environment, culture and health status. Hum Ecol 1 (1974) 245277.

43. Smith BE. Black lung: The social production of disease. Int J Health Serv 11 (1981) 343-359.

44. Sterling TD. Does smoking kill workers or working kill smokers? Int J Health Serv 8 (1978) 437-451.

45. Syme SL, Berkman LF. Social class, susceptibility and sickness. Am J Epidemiol 104 (1976) 1-8.

46. Turner-Warwick $M$. The scope of the problem. In: Weill $\mathrm{H}$, Turner-Warwick $\mathrm{M}$, ed. Occupational lung diseases. Marcel Dekker, New York, NY 1981, pp $1-10$.

47. US Department of Health Education and Welfare. Respiratory diseases: Task force report on prevention, control, education. Washington, DC 1977, p 9. (Publication no NIH 77-1248)

48. US Department of Health Education and Welfare. NIAID task force report: Asthma and the other allergic diseases. Washington, DC 1979. (Publication no DHEW (NIH) 79-287).

49. US Department of Health, Education and Welfare. Epidemiology of respiratory disease. Washington, DC 1979. (Publication no NIH 81-2019).

50. US Department of Health and Human Services. Report of workshop on lung disease and behavior. Washington, DC 1983.

51. US Department of Labor, Occupational Safety \& Health Administration. Physical ability. Washington, DC 1976. (OSHA safety and health standards (29 CFR 1910)).

52. Vinni K. Occupational morbidity based on social insurance records in Finland. Scand J Soc Med 11 (1983) $41-52$.

53. Winkelstein W, Kantor S, Davis EW, Maneri CS, Mosher WE. Relationship of air pollution and economic -status to total mortality and selected respiratory system mortality in men. Arch Environ Health 14 (1967) 162-171.

54. Woolock AJ, Blackburn CRB, Freeman MH, Zylstra $\mathrm{W}$, Spring SR. Studies of chronic lung disease in New Guinea populations. Am Rev Respir Dis 102 (1970) 575.

55. World Health Organization. Long(term) programme in environmental pollution control in Europe. Copenhagen 1972.

56. World Health Organization. Health effects of combined exposures in the work environment. Geneva 1981. (WHO tech rep 662).

57. Wyatt JP. Environmental factors in CLD. In: Lee DHK, ed. Environmental factors in respiratory disease. Academic Press, New York, NY 1972, pp 126127.

58. Ecology of chronic non-specific respiratory diseases: International symposium. Panstwowy Zaklad Wydawnictw Lekarsckich, Warsaw 1972. 240 p.

59. - Symposium proceedings on occupational immunologic lung disease, Washington, DC. J Allergy Clin Immunol 70 (1982) $1-72$. 